\title{
Breast feeding and cognitive development at age 1 and 5 years
}

\author{
N K Angelsen, T Vik, G Jacobsen, L S Bakketeig
}

\begin{abstract}
Aim-To examine whether duration of breast feeding has any effect on a child's cognitive or motor development in a population with favourable environmental conditions and a high prevalence of breast feeding.

Methods-In 345 Scandinavian children, data on breast feeding were prospectively recorded during the first year of life, and neuromotor development was assessed at 1 and 5 years of age. Main outcome measures were Bayley's Scales of Infant Development at age 13 months (Mental Index, MDI; Psychomotor Index, PDI), Wechsler Preschool and Primary Scales of Intelligence (WPPSI-R), and Peabody Developmental Scales at age 5 .

Results-Children breast fed for less than 3 months had an increased risk, compared to children breast fed for at least 6 months, of a test score below the median value of MDI at 13 months and of WPPSI-R at 5 years. Maternal age, maternal intelligence (Raven score), maternal education, and smoking in pregnancy were significant confounders, but the increased risk of lower MDI and total IQ scores persisted after adjustment for each of these factors. We found no clear association between duration of breast feeding and motor development at $\mathbf{1 3}$ months or 5 years of age.
\end{abstract}

Conclusion-Our data suggest that a longer duration of breast feeding benefits cognitive development.

(Arch Dis Child 2001;85:183-188)

Keywords: breast feeding; motor skills; mental development

Community Medicine, Norwegian University of Science and

Technology, N-7489

Trondheim, Norway

K Angelsen

T Vik

G Jacobsen

Institute of Public Health, University of Southern Denmark B Odense University, Sdr. Boulevard 23A,

DK-5000 Odense C,

Denmark

L S Bakketeig

Correspondence to:

Dr Vik

torstein.vik@medisin.ntnu.no

Accepted 8 May 2001

Child cognitive development is influenced by genetic and environmental factors. ${ }^{1}$ The child has a genetically determined potential for cognitive development. However environmental factors, such as adequate nutrition and the parents' ability to create a good and stimulating home environment may also have a positive influence on the child's cognitive development. $^{2}$

Several studies have shown a positive correlation between breast feeding and cognitive development in children. ${ }^{3-14}$ However, a number of confounders represent problems in these studies. Mothers who breast feed tend to be older, have a better education, and a higher socioeconomic status, than mothers who breast feed their children for a limited time or not at all. ${ }^{315}$ In some studies the association between breast feeding and cognitive development is not statistically significant after adjustment for such confounders. ${ }^{16-20}$

A recent meta-analysis ${ }^{21}$ concluded that breast feeding is associated with significantly higher scores for cognitive development than was formula feeding, after adjustment for confounding factors. This meta-analysis included mainly studies that compared children who had been breast fed with children who were exclusively formula fed.

However, few studies have compared the effect of the duration of breast feeding in societies where almost all infants are breast fed for at least some weeks. In Scandinavia nearly $100 \%$ of mothers start breast feeding and more than $50 \%$ are still breast feeding six months after birth. ${ }^{15}$ Moreover, compared to other regions in the world, this population is in general considered to be relatively homogeneous in terms of socioeconomic status, being highly educated, having little poverty, and a good public health care and social security system. Under these otherwise favourable environmental conditions it may be questioned whether duration of breast feeding has any effect on cognitive development.

Against this background we wished to test the following null hypotheses:

(1) There is no difference in mental development at 13 months and 5 years between children who were breast fed for less than three months compared to children who were breast fed for at least six months.

(2) There is no difference in motor development at 13 months and 5 years between children who were breast fed for less than three months compared to children who were breast fed for at least six months.

\section{Materials and methods} DESIGN
This study is part of a population based prospective study in Trondheim and Bergen, Norway, and Uppsala, Sweden. Details of the study have been reported elsewhere. ${ }^{22}$

Enrolment took place between 1 January 1986 and 31 March 1988. Those eligible were white, para 1 and para 2 women (women with one or two previous births, respectively) who had a singleton pregnancy and who could be registered prior to the 20th week of gestation. At study entry, the women gave information about age, smoking habits, and education. The regional ethics committees for medical research approved the study and written informed consent was obtained from the women.

In the present study, we used data from the children of a $10 \%$ randomly chosen group of the women, selected at study entry. Children 
who were born before week 37 of gestation and children who had congenital malformations were excluded from the analysis.

Data on breast feeding were collected by public health nurses at 6 weeks, and 3,6 , and 9 months of age, and were recorded on research questionnaires that were prospectively returned to the project. At each examination, the mothers were asked to indicate whether they were still breast feeding or not. If not, they were asked to indicate the age they had stopped. Questions on additional feeding (including formula feeding) were also asked, but the answers were not quantifiable. At age 13 months, data on breast feeding and additional nutrition were collected in the same manner by a project paediatrician, and in addition the mothers were asked to retrospectively record the duration of exclusive breast feeding. The prospectively recorded "yes" or "no" answers at 6 weeks, and 3, 6, 9, and 13 months of age were considered as the qualitatively best data and used in the following analyses.

At age 13 months, a psychometrist assessed the children's mental and psychomotor development, using the Bayley Scales of Infant Development (BSID), ${ }^{23}$ while the mothers completed the Home Screening Questionnaire (HSQ). ${ }^{24}$

At age 5 years, a psychometrist assessed the children's cognitive abilities, using the Wechsler Preschool and Primary Scales of Intelligence (WPPSI-R), ${ }^{25}$ and a paediatrician used the Peabody Developmental Motor Scales (PDMS) to assess the children's motor abilities. ${ }^{26}$ The mothers were tested with Raven's Progressive Matrices, ${ }^{27}$ and family income was recorded.

The examiners were not aware of information concerning infant feeding, nor of the hypotheses tested in the present study.

\section{STUDY POPULATION}

Of 6354 women referred to the project, 432 were not eligible for the study, and $200(3 \%)$ failed to attend the first appointment; thus a total of 5722 women were included in the multicentre study. A total of $561(10 \%)$ women were randomly selected for follow up at study entry. When children born before the 37 th week of gestation $(n=24)$ and children who had congenital malformations $(n=16)$ were excluded, 521 children were eligible for follow up in the principal study.

Of the 521 children eligible for follow up, 365 had a Bayley's test at 13 months of age. These 365 children did not differ in terms of birth weight, length, head circumference, or gestational age from the 156 children who were not tested. The mothers of included children were on average $1.3 \mathrm{~cm}$ taller than those not included, whereas there were no differences in prepregnancy weight, age, level of education, and number of cigarettes smoked at conception (data not shown). Data on breast feeding at 3 and 6 months of age were available for 345 of the children. No differences in anthropometric, sociodemographic, or perinatal variables were found between the groups who had $(n=345)$ or who lacked $(n=20)$ data on breast feeding. In particular, Bayley's developmental indexes of the children were identical $(p=0.8)$. Fifty nine $(17 \%)$ of the 345 children were breast fed for less than three months and $214(62 \%)$ were breast fed for at least six months.

Of the 345 children with complete data at age 13 months, 291 were tested with the WPPSI-R and 284 with the PDMS. The proportion of children breast fed for less than three months tested at 5 years of age, was the same as for the children tested with BSID. Moreover, there were no differences in background variables between the 291 who completed and the 54 children who did not complete the WPPSI-R test, or between children ( $n=284)$ who completed and children $(n=61)$ who did not complete the PDMS.

\section{DEFINITIONS}

Information concerning infant feeding was prospectively recorded at the public health routine controls at 6 weeks and 3, 6, 9, and 13 months of age. Duration of breast feeding was classified into three categories based on whether the child was still breast fed at 3 or 6 months of age. The first group was not breast fed at three months. The second group was breast fed at three months, but not at six months. The last group was still breast fed at the six month control.

Table 1 Characteristics of mothers and children and duration of breast feeding

\begin{tabular}{|c|c|c|c|c|}
\hline & \multicolumn{4}{|l|}{ Breast feeding at: } \\
\hline & $<3$ months & 3-6 months & $\geqslant 6$ months & p value \\
\hline Number breast fed & 59 & 72 & 214 & \\
\hline \multicolumn{5}{|l|}{ Mother } \\
\hline Maternal age & $28.0(3.5)$ & $29.0(3.8)$ & $29.6(3.9)^{\star}$ & 0.011 \\
\hline Raven score & $46.8(6.6)$ & $47.6(8.0)$ & $49.7(5.9) \dagger$ & 0.019 \\
\hline HSQ score & $34.7(3.6)$ & $35.1(2.4)$ & $35.6(3.0)$ & 0.209 \\
\hline Maternal income $\$$ & $9692 \quad(4076)$ & $9565 \quad(5105)$ & $10985 \quad(5555)$ & 0.135 \\
\hline Paternal income & $17497 \quad(6956)$ & $19205 \quad(7995)$ & $20114 \quad(8412)$ & 0.184 \\
\hline \multicolumn{5}{|l|}{ Child } \\
\hline Birth weight (g) & $3592 \quad(494)$ & $3642 \quad(548)$ & $3679 \quad(529)$ & 0.239 \\
\hline Length $(\mathrm{cm})$ & $50.6(2.0)$ & $51.3(2.0)$ & $51.0(2.2)$ & 0.244 \\
\hline Head circumference $(\mathrm{cm})$ & $35.4(1.2)$ & $35.3(1.2)$ & $35.3(1.3)$ & 0.937 \\
\hline Gestational age (wk) & $39.7(1.3)$ & $39.7(1.3)$ & $39.6(1.2)$ & 0.866 \\
\hline
\end{tabular}

Results expressed as mean (SD)

$\star$ Significantly different from $<3$ months $(p=0.013$, Scheffé's test).

†Significantly different from $<3$ months $(p=0.05$, Scheffé's test).

$\ddagger$ Home Screening Questionaire.

IIncome per month (NOK). 
Table 2 Bayley Scales of Infant Development at 13 months and duration of breast feeding (BF)

\begin{tabular}{|c|c|c|c|c|c|c|}
\hline & \multicolumn{4}{|c|}{ Duration of $B F$} & \multicolumn{2}{|l|}{ ANOVA } \\
\hline & $<3$ months & $3-6$ & $\geqslant 6$ & Total & pvalue & $p$ for trend \\
\hline Number BF & 59 & 72 & 214 & 345 & & \\
\hline MDI & $109.9(13.1)$ & $114.3(10.4)$ & $117.7(11.7)^{\star}$ & $115.7(11.7)$ & $<0.001$ & $<0.001$ \\
\hline PDI & $103.4(13.3)$ & $107.3(14)$ & $107.9(14.2)$ & $107.0(14.1)$ & 0.093 & 0.044 \\
\hline
\end{tabular}

Results expressed as mean (SD).

*Significantly different from $<3$ months $(\mathrm{p}<0.001$; Sheffé's test).

MDI, Mental Developmental Index; PDI, Psychomotor Developmental Index.

The mother's level of education was dichotomised as "high" or "low": more than 12 years of education was defined as a high level of education, whereas 12 years or less was defined as low.

Test results were dichotomised, creating two groups of children by choosing a cut off point at the median value for the whole study population. For Bayley scales the median indexes were 116 (mental) and 110 (psychomotor), and for WPPSI-R 110 (total IQ), 111 (performance IQ), and 105 (verbal IQ). A test score below this value is defined as low, while a score equal to or above it, is defined as high.

MISSING BACKGROUND DATA

Maternal data were complete (in the range from 340 to 345) for the 345 children included in this study, except for maternal Raven score $(\mathrm{n}=238)$ and monthly income $(\mathrm{n}=252)$. However, there was no difference in maternal age, level of education, number of cigarettes smoked at conception, birth weight of the child, duration of breast feeding, or the child's IQ (Bayley's test at 13 months, WPPSI-R at 5 years of age) between mothers who completed and who did not complete the Raven test, or between mothers who provided and mothers who did not provide information of income (data not shown).

STATISTICAL ANALYSIS

For variables with normal distribution, one way analysis of variance was used to compare mean values. If a difference was detected, Sheffé's test was used as post hoc test. For variables without normal distribution the KruskalWallis test was used. ${ }^{28}$

Odds ratio (OR) was calculated and used as an estimate of the relative risk of getting a low test score among children who had been breast fed less than three months, compared to children who had been breast fed at least six months. Precision of the odds ratio was estimated by $95 \%$ confidence intervals (CI), using Mantel-Haenzel $\chi^{2}$ statistics. ${ }^{29}$

We also applied logistic regression analysis to calculate adjusted odds ratios, ${ }^{28}$ in order to control for possible confounding factors.

With a power of $80 \% \quad(\beta=0.20)$ and $\alpha=0.05$, this study may detect a 4.8 point difference in MDI and a 6.7 point difference in total IQ score (WPPSI-R).

\section{Results}

Maternal age and maternal Raven score were positively associated with duration of breast feeding (table 1). The proportion of mothers with low education was higher among mothers
Table 3 Estimates of the risk (odds ratio) of getting a "low" Bayley score at 13 months of age among children breast fed for less than 3 months compared to children who were breast fed for 6 months or more

\begin{tabular}{|c|c|c|c|}
\hline & \multicolumn{3}{|c|}{ Duration of breast feeding } \\
\hline & $\begin{array}{l}<3 \text { months } \\
n\end{array}$ & $\begin{array}{l}\geqslant 6 \text { months } \\
n\end{array}$ & $\begin{array}{l}\text { OR } \\
(95 \% C I)\end{array}$ \\
\hline \multicolumn{4}{|l|}{ MDI } \\
\hline Low & 39 & 81 & $3.2(1.7-5.9)$ \\
\hline High & 20 & 133 & \\
\hline \multicolumn{4}{|l|}{ PDI } \\
\hline Low & 33 & 99 & $1.5(0.8-2.6)$ \\
\hline High & 26 & 115 & \\
\hline
\end{tabular}

who breast fed for less than three months $(64 \%)$ than among mothers who breast fed for at least six months $(34 \%)(p<0.001)$. The proportion of smokers was $61 \%$ among mothers who breast fed for less than three months, compared to $24 \%$ in mothers who breast fed for at least six months $(\mathrm{p}<0.001)$. The scores on the HSQ, the parents' income, gestational age, and anthropometric measurements of the child at birth were not associated with the duration of breast feeding.

DEVELOPMENT AT AGE 13 MONTHS

The mean mental developmental index was lower in children breast fed for less than three months compared to children breast fed for at least six months (table 2). The mean difference between the groups was 7.8 points $(95 \% \mathrm{CI}$ : 3.7 to $11.9 ; \mathrm{p}<0.001)$. When data from the group breast fed between three and six months were included, there was a linear increase in the mental development index $(p<0.001)$. The psychomotor index did not differ significantly between the groups $(p=0.09)$, although there was a trend $(\mathrm{p}<0.05)$ towards increasing scores with increasing duration of breast feeding.

Children breast fed for less than three months had a higher risk, compared to children who were breast fed for at least six months, of a lower mental developmental index $(\mathrm{OR}=3.2$; 95\% CI: 1.7 to 5.9 ; table 3 ). The risk for children breast fed for less than three months of a low psychomotor index was, in contrast, not significantly increased.

The only factor in this study, related to duration of breast feeding, which was also related to child development at 13 months, was maternal Raven score (data not shown). Adjustment for differences in maternal Raven score reduced the OR of having a low mental development index among children who were breast fed for less than three months to 1.6 (95\% CI: 1.1 to 2.3 ; table 4 ). 
Table 4 Estimates of the risk (odds ratio) of getting a "low" Bayley score at age 13 months among children breast fed for less than 3 months compared to children breast fed for at least 6 months, and odds ratio adjusted for maternal age, education, smoking, and Raven score

\begin{tabular}{|c|c|c|c|}
\hline & \multirow[b]{2}{*}{$n$} & \multicolumn{2}{|l|}{$O R(95 \% C I)$} \\
\hline & & $M D I$ & $P D I$ \\
\hline Breast feeding alone & 273 & $3.2(1.7-5.9)$ & $1.5(0.8-2.6)$ \\
\hline Breast feeding + mother's age & 268 & $1.7(1.3-2.4)$ & $1.2(0.9-1.6)$ \\
\hline Breast feeding + education & 271 & $1.8(1.3-2.5)$ & $1.2(0.9-1.6)$ \\
\hline Breast feeding + smoking & 272 & $1.9(1.3-2.6)$ & $1.1(0.8-1.5)$ \\
\hline Breast feeding + Raven score & 193 & $1.6(1.1-2.3)$ & $1.3(0.9-1.8)$ \\
\hline
\end{tabular}

MDI, Mental Developmental Index; PDI, Psychomotor Developmental Index.

Table 5 WPPSI-R score at 5 years of age and duration of breast feeding (BF)

\begin{tabular}{|c|c|c|c|c|c|c|}
\hline & \multicolumn{3}{|c|}{ Duration of $B F$} & \multicolumn{3}{|l|}{ ANOVA } \\
\hline & $<3$ months & 3-6 months & $\geqslant 6$ months & Total p & $p$ for tren & \\
\hline Number BF & 49 & 61 & 183 & $293^{\star}$ & & \\
\hline Total IQ & $103.6(14.6)$ & $107.9(17.2)$ & $111.0(14.3) \dagger$ & $109.1(15.2)$ & 0.007 & 0.002 \\
\hline Verbal IQ & $100.4(13.9)$ & $103.9(15.4)$ & $106.1(14.4)$ & $104.7(14.6)$ & 0.047 & 0.014 \\
\hline Performance IQ & $106.1(15.1)$ & $109.4(16.8)$ & $113.4(14.1) \dagger$ & $111.3(15.1)$ & 0.005 & 0.001 \\
\hline
\end{tabular}

Results expressed as mean (SD).

*Two children did not complete the WPPSI-R-test.

†Significantly different from $<3$ months $(\mathrm{p}<0.001$, Sheffé's test).

MDI, Mental Developmental Index; PDI, Psychomotor Developmental Index.

Table 6 Estimates of the risk (odds ratio) of getting a "low" WPPSI-R score at age 5 years among children breast fed for less than 3 months compared to children breast fed for six months or more, adjusted for maternal age, education, smoking, and Raven score

\begin{tabular}{lllll}
\hline & \multicolumn{4}{l}{ OR (95\% CI) } \\
\cline { 3 - 5 } \cline { 3 - 5 } & $n$ & Total IQ & Verbal IQ & Performance IQ \\
\hline Breast feeding alone & 231 & $2.8(1.4-5.3)$ & $1.4(0.7-2.6)$ & $2.2(1.1-4.1)$ \\
Breast feeding + age & 228 & $1.6(1.1-2.2)$ & $1.1(0.8-1.5)$ & $1.5(1.1-2.1)$ \\
Breast feeding + education & 230 & $1.6(1.1-2.3)$ & $1.1(0.8-1.5)$ & $1.4(1.0-2.0)$ \\
Breast feeding + smoking & 231 & $1.6(1.2-2.3)$ & $1.1(0.8-1.6)$ & $1.4(1.0-2.0)$ \\
Breast feeding + Raven score & 192 & $1.5(1.0-2.1)$ & $1.0(0.7-1.5)$ & $1.2(0.8-1.7)$ \\
\hline
\end{tabular}

MENTAL DEVELOPMENT AT AGE 5 YEARS

The mean total IQ was lower in children breast fed for less than three months compared to children breast fed for at least six months ( $\mathrm{p}=0.007$; table 5).

Children breast fed for less than three months had a higher risk, compared to children breast fed for at least six months, of having a low total IQ $(\mathrm{OR}=2.8 ; 95 \% \mathrm{CI}: 1.4$ to 5.3$)$. For the subscale "performance IQ", children breast fed for less than three months had a higher risk, compared to children breast fed for at least six months, of having a low IQ score $(\mathrm{OR}=2.2 ; 95 \% \mathrm{CI}: 1.1$ to 1.4$)$. For "verbal IQ" there was no difference in risk of having a low IQ score (OR $=0.7 ; 95 \% \mathrm{CI}$ : 0.7 to 2.6 ).

Factors related to both duration of breast feeding and child development at five years were maternal education, Raven score, maternal age, and smoking at the time of conception (data not shown). These possible confounders were included in a logistic regression analysis (table 6). Adjustment for differences in Raven score reduced the OR of having a low total IQ score to 1.5 (95\% CI: 1.0 to 2.1$)$. When analysing performance IQ and verbal IQ separately, the risk for children breast fed for less than three months to have a IQ score below the median value, was not statistically different from the other children when adjusting for maternal Raven score (table 6).

\section{MOTOR DEVELOPMENT AT AGE 5 YEARS}

Table 7 shows the median values of motor development obtained from the PDMS. There was a borderline statistically significant difference in balance scores associated with different lengths of breast feeding, whereas no association was found between duration of breast feeding and the two other motor development tests.

\section{Discussion}

In this study, we have to reject the null hypothesis of no association between duration of breast feeding and mental development. Instead we found that a shorter duration of breast feeding was associated with lower scores on mental developmental tests both at 13 months and at 5 years of age. For motor development, we cannot reject the null hypothesis, even though we found borderline significant trends towards lower scores on motor developmental tests both at 13 months, and at 5 years of age (balance score).

Children included in this study were randomly selected, and the mothers were not aware of the breast feeding hypotheses when they agreed to participate. We were not able to show differences in essential characteristics between children included and those not included, or between their mothers. Moreover, information on breast feeding was given prospectively and the examiners did not know the duration of breast feeding, nor were they aware of the hypothesis. Bias is therefore unlikely as an explanation of the association of duration of breast feeding and mental development in this study.

There is a possibility that some children who were classified as breast fed for at least six months may actually have been breast fed for a shorter duration, or that children classified as breast fed for less than six months may have been breast fed longer. Such misclassification would most likely have led to an underestimation of the difference between the groups.

Multivariate analysis suggested that maternal age, maternal education, and maternal intelligence (Raven score) were significant confounders of this association. Not all mothers completed the Raven test, and this raises the possibility of a non-random selection. However, we were not able to find any

Table 7 Peabody Developmental Motor Scales (PDMS) in 5 year old children and duration of breast feeeding

\begin{tabular}{lccccc}
\hline Duration of $B F$ & $<3$ months & $3-6$ months & $\geqslant 6$ months & Total & $p$ value \\
\hline Number BF & 49 & 60 & 175 & $284^{\star}$ & $61(48-114)$ \\
PDMS Balance & $59(48-64)$ & $62(50-66)$ & $61(48-114)$ & 0.058 \\
PDMS Locomotion & $107(86-114)$ & $109(93-114)$ & $108(82-114)$ & $108(82-114)$ & 0.215 \\
PDMS Eye-hand coordination & $85(67-91)$ & $84(68-92)$ & $86(73-92)$ & $85(67-92)$ & 0.128 \\
\hline
\end{tabular}

Results expressed as median (range).

${ }^{\star}$ A few children did not complete all subscales of the PDMS. 
difference between mothers who completed and those who did not complete this test or between their children. Moreover, although this reduced the power of the multivariate analysis, the increased risk of low MDI and total IQ scores associated with a shorter duration of breast feeding persisted after adjustment for each of the confounders, including the Raven score.

Our results are consistent with several larger studies $^{3-14}$ in various communities in developed countries, using a number of developmental tests, which have shown a positive association between breast feeding and cognitive development of the child, even after adjustment for confounding factors. However, some smaller studies ${ }^{16-19}$ published in recent years and one larger study $(\mathrm{n}=1037)^{20}$ showed that breast feeding had no beneficial effect on mental development after adjusting for confounding factors.

In October 1999, a meta-analysis including 20 studies from 1966 to 1996 showed that breast feeding was associated with significant higher scores on cognitive development tests. ${ }^{21}$ Adjusting for several confounders, the mean difference between breast fed children and children who had been exclusively bottle fed was 3.16 points ( $95 \%$ CI: 2.35 to 3.98 ).

Most previous studies have compared breast fed children with children who were exclusively formula fed, but some studies have found that the correlation between breast feeding and cognitive ability increases with a longer duration of breast feeding. ${ }^{313} 30$ A Finnish study of 1163 children found a mean difference of 2.4 points on a cognitive test at 6 months of age between children breast fed for less than five months, compared to children breast fed for at least five months. ${ }^{10}$

The small differences in IQ points between breast fed and bottle fed children, ${ }^{21}$ and between children breast fed for less than five months or more than five months, ${ }^{10}$ are unlikely to have clinical significance. Similarly, the unadjusted difference of 8 points between children who were breast fed for less than 3 months, compared to those who were breast fed for six months or more, is unlikely to have clinical significance in a population with a mean IQ at age 5 of 109 points. However, it may suggest that factors associated with breast feeding are necessary for optimal cognitive development.

The linear association over three time periods (table 2) between breast feeding and mental development suggests a dose-response relation which may be consistent with a causal relation. There is a possibility that the intimacy of breast feeding is important for infant development. ${ }^{13}$ However, human milk contains biological factors that may be beneficial for mental development, ${ }^{31-34}$ including biologically active peptides and essential long chain polyunsaturated fatty acids. Neural growth factors and insulin like growth factors are examples of biologically active peptides which may influence brain growth. Whether these factors reach the target tissues in the infant and whether they affect brain development is not clear. ${ }^{31}$
Human milk has a high content of long chain polyunsaturated fatty acids, especially docosahexaenoic and arachidonic acid. A recent study has reported an association between dietary long chain polyunsaturated fatty acids and mental development in infants. ${ }^{32}$ It has been suggested that these fatty acids can be an explanation for the beneficial effect of nutrition with human milk on mental development of the child. ${ }^{33} 34$ This may be a plausible biological explanation of the correlation between breast feeding and mental development.

\section{MOTOR DEVELOPMENT}

We found no clear association between duration of breast feeding and motor development at 13 months or 5 years of age. Previous studies of breast feeding and motor development are consistent with this. ${ }^{835-37}$ However, a recent Danish study of 1656 children found that motor milestones were achieved at an earlier age in breast fed than in formula fed infants. ${ }^{38}$ We found borderline significant associations between duration of breast feeding and motor development. As our study has a power of $80 \%$ $(\alpha=0.05)$ to detect a difference of at least 5.7 points for the Bayley PDI and 2.6 points for the Peabody motor scales, we cannot exclude a small positive effect of breast feeding on motor development.

\section{CONCLUSION}

In this study of a population of relatively high socioeconomic status, we found a positive association between duration of breast feeding and mental development, even after adjusting for maternal age, maternal education, maternal intelligence (Raven score), and smoking at the time of conception. We found no association between duration of breast feeding and motor development at 13 months or 5 years of age. Our data support the hypothesis that a longer duration of breast feeding benefits cognitive development.

The US National Institute of Child Health and Human Development, NIH (NICHD contract no. 1-HD-4-2803, and no.1-hd-1-3127) supported this study.

1 Berndt TJ. Child development. Orlando: Harcourt Brace Javanovich, 1992.

2 Bacahrach VR, Baumeister AA. Effects of marital intelligence, marital status, income and home environment on cognitive development of low birthweight infants. 7 Pediatr Psychol 1998;23:197-205.

3 Horwood J, Fergusson D. Breast-feeding and later cognitive and academic outcomes. Pediatrics 1998;101:e9.

4 Golding J, Rogers IS, Emmett PM. Association between breast feeding, child development and behaviour. Early breast feeding, child developm
Hum Dev 1997;49:S175-84.

5 Rodgers B. Feeding in infancy and later ability and Rodgers B. Feeding in infancy and later ability and
attainment: a longitudinal study. Dev Med Child Neurol attainment: a long

6 Fergusson DM, Beautrais AL, Silva P. Breast feeding and cognitive development in the first 7 years of life. Soc Sci Med 1982;16:1705-8.

7 Taylor B, Wadsworth J. Breast-feeding and child development at 5 years. Dev Med Child Neurol 1984;26:73-80.

8 Rogan WJ, Gladen BC. Breast feeding and cognitive development. Early Hum Dev 1993;31:181-93.

9 Pollock JI, Long term associations with infant feeding in a clinically advantaged population of babies. Dev Med Child Neurol 1994;36:429-40.

10 Niemelä A, Jarvenpaa AL. Is breastfeeding beneficial and maternal smoking harmful to the cognitive development of children? Acta Paediatr 1996;85:1202-6.

11 Morley R, Cole TJ, Powell R, Lucas A. Mother's choice to provide breast milk and developmental outcome. Arch Dis Child 1988;63:1382-5.

12 Lucas A, Morley R, Cole TJ, et al. Early diet in preterm babies and developmental status at 18 months. Lancet 1990;335:1477-81. 
13 Lucas A, Morley R. Breast milk and subsequent intelligence quotient in children born preterm. Lancet 1992:339:261-4. 14 Lucas A, Morley R, Cole TJ, Gore SM. A randomised multicentre study of human milk versus formula and later development in preterm infants. Arch Dis Child Fetal Neonatal Ed 1994,70:F141-6.

15 Michaelsen KF, Larsen, Thomsen BL, Samuelson G. The Copenhagen cohort study on infant nutrition and growth duration of breast feeding and influencing factors. Acto Paediatr 1994;83:565-71.

16 Malloy M, Berendes H. Does breast-feeding influence intelligence quotients at 9 and 10 years of age? Early Hum Dev 1998;50:209-17.

17 Richards M, Wadsworth M, Rahimi-Foroushani A, et al. Infant nutrition and cognitive development in the first offspring of a national UK birth cohort. Dev Med Child Neurol 1998;40:163-7.

18 Jacobson SW, Jacobson JL. Breast feeding and intelligence. Lancet 1992;339:926.

19 Jacobson SW, Chiodo LM, Jacobson JL. Breastfeeding effects on intelligence quotient in 4- and 11-year old child

20 Silva PA, Buckfield P, Spears GF. Some maternal and child developmental characteristics associated with breast feeding: a report from the Dunedin Multidisciplinary Child Development Study. Aust Paediatr F 1978;14:265-8.

21 Anderson JW, Johnstone BM, Remley DT. Breast-feeding and cognitive development: a meta-analysis. Am f Clin Nutr 1999;70:525-35.

22 Bakketeig L, Jacobsen G, et al. Pre-pregnancy risk factors of small-for-gestational age births among parous women in Scandinavia. Acta Obstet Gynecol Scand 1993;72:273-9.

23 Bayley N. Bayley scales of infant development. New York: The Psychological Corporation, 1969.

24 Frankenburg WK, Coons MA. Home Screening Questionaire: its validity in assessing home environment. $\mathcal{F}$ Pediatr 1986;108:624 B6.

25 Wechsler D. Manual for the Wechsler preschool and primary scale of intelligence. New York: Psychological Corporation, 1989.
26 Folio MR, Fewell RR. Peabody Developmental Motor Scales and Activity Cards. Manual. Allen: DLM Teaching Resources, 1983 .

27 Raven J. Progressive matrices. London: HK Lewis 1965.

28 Kleinbaum DG, Kupper LL, Morgenstern H. Epidemiologic research. New York: Van Nostrand Reinhold Company, 1982:419-46.

29 Altman DG. Practical statistics for medical research. London: Chapman and Hill, 1991.

30 Morrow-Tlucak M, Haude RH, Ernhart CB. Breastfeeding and cognitive development in the first 2 years of life. Soc Sci Med 1988;26:635-9.

31 Morley R, Lucas A. Nutrition and cognitive development. Br Med Bull 1997;53:123-34.

32 Birch EE, Garfield S, Hoffman D, et al. A randomized controlled trial of early dietary supply of longchain polyunsaturated fatty acids and mental development in term infants. Dev Med Child Neurol 2000;42:174-81.

33 Crawford MA. The role of essential fatty-acids in neural development-implications for perinatal nutrition. $A m \mathcal{F}$ Clin Nutr 1993;57:S703-10.

34 Xiang $M$, Alfvèn $G$, Blennow $M$, et al. Long-chain polyunsaturated fatty acids in human milk and brain growth during early infancy. Acta Paediatr 2000;89:142-7.

35 Temboury MC, Otero A, Polanco I, Arribas E. Influence of breast-feeding on the infant's intelectual development. $\mathcal{F}$ Pediatr Gastroenterol Nutr 1994;18:32-6.

36 Florey C du V, Leech AM, Blackhall A. Infant feeding and mental and motor development at 18 months of age in first born singletons. Int $\mathcal{F}$ Epidemiol 1995;24:S21-6.

37 Paine BJ, Makrides M, Gibson RA. Duration of breastfeeding and Bayley's mental developmental index at 1 year of age. F Paediatr Health 1999;34:82-5.

38 Vestergaard M, Obel C, Henriksen TB, et al. Duration of breastfeeding and developmental milestones during the latter half of infancy. Acta Paediatr 1999;88:1327-32.

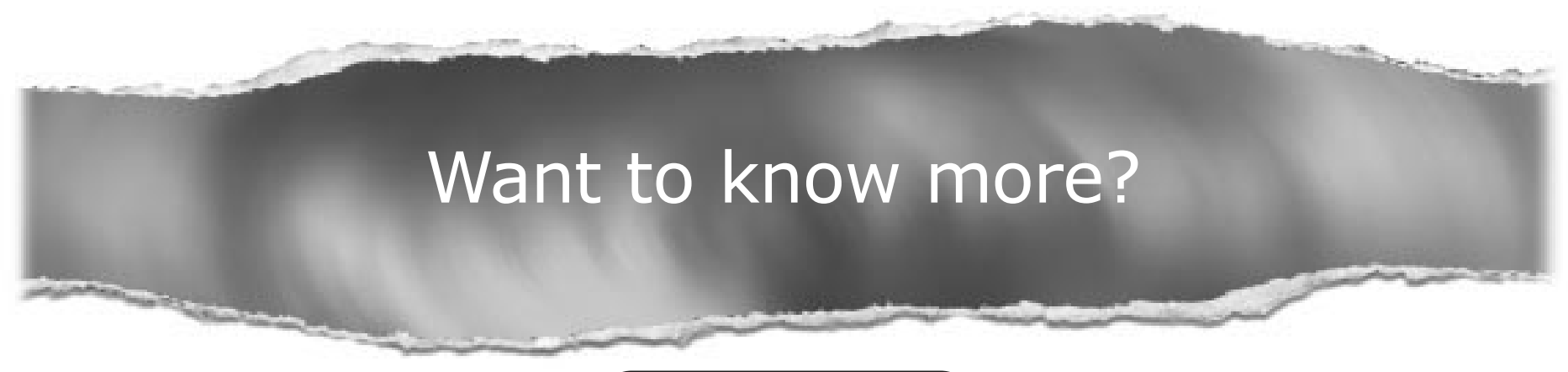

Data supplements

Limited space in printed journals means that interesting data and other material are often edited out of articles; however, limitless cyberspace means that we can include this information online.

Look out for additional tables, references, illustrations.

www.archdischild.com 